\title{
Al writing bots are about to revolutionise science journalism: we must shape how this is done
}

\section{Mico Tatalovic}

\begin{abstract}
The rise of artificial intelligence has recently led to bots writing real news stories about sports, finance and politics. As yet, bots have not turned their attention to science, and some people still mistakenly think science is too complex for bots to write about. In fact, a small number of insiders are now applying Al algorithms to summarise scientific research papers and automatically turn them into simple press releases and news stories. Could the science beat be next in line for automation, potentially making many science reporters - and even editors - superfluous to science communication through digital press? Meanwhile, the science journalism community remains largely unaware of these developments, and is not engaged in directing $\mathrm{Al}$ developments in ways that could enhance reporting.
\end{abstract}

Keywords

DOI
Science and media; Science and technology, art and literature; Science writing

https://doi.org/10.22323/2.17010501
It's time for the science journalism and PR communities to wake up to the opportunities and threats posed to their professions by the recent explosion in the progress of artificial intelligence. Over the past few months, I have spoken to experts in the world of AI and journalism, as part of my Knight Science Journalism fellowship at MIT. Two things struck me as especially surprising. One is just how close we are to AI bots that can both write and edit the science stories that most science journalists and science press officers make a living out of writing and editing. This technology is available, but so far few have thought to apply it to science. This is about to change.

The second surprise was just how few science journalists are aware of the potential of AI bots, or take an interest in them. My colleagues on the KSJ fellowship have made light of the issue by joking that my project will kill off their jobs. But here's the thing: similar projects will inevitably soon revolutionise much of science news reporting, and likely eliminate entry-level jobs the community relies on as a first step into the profession. So what is happening, and what should science writers be doing about it?

Over the last five years or so, there has been a steep rise in news stories generated by bots which have been developed by software engineers and coders. Some of us 
saw the LA Times' quakebot in 2014 as a one-off gimmick generating super-short alerts with minimum information: a quake over a certain size has struck an area nearby [Oremus, 2014]. But now, bots have been developed that routinely report on sports results, financial reports, and even elections, in stories several paragraphs long. Elsewhere, AI programs have already written a novel shortlisted for a literary award [Olewitz, 2016], directed movies and TV shows [Sawer, 2017], and helped write science fiction stories [Marche, 2017].

Several big media organisations such as the Associated Press and Washington Post employ developers that make and maintain such bots [e.g. Miller, 2015]. And while the practice is not widespread yet, it is slowly spreading to those who can afford to hire pricey AI developers (the associated costs may create a two-tier media system of have and have-nots in the short term, until cheaper off-the-shelf bots become available).

Algorithms and AI are playing an increasingly important role in all aspects of our society and journalists must understand them in order to grasp what's going on in the world, to be able to provide "algorithmic accountability", said Nicholas Diakopoulos, Assistant Professor at Northwestern University, and Director of its Computational Journalism Lab in his talk at the European Investigative Journalism Conference in Mechelen, Belgium, last year.

But most journalists and media are unprepared to take advantage of these technologies as they lack the know-how and fail to plan strategically for innovations and technological change, according to Amy Webb, professor of strategic foresight at the NYU Stern School of Business and founder of the Future Today Institute. Her Global Survey of Journalism's Future in 2017 found that few news organisations are thinking about the mid- to long-term future of news in the coming age of AI, automation and voice-based computing [Webb, 2017]. Almost $70 \%$ say that their newsrooms are not conducting analysis of emerging tech trends and how they will impact news in the next $5-10$ years.

As a result, journalists are deeply concerned that they won't be prepared for new communication technologies, that the business models of their organizations won't be relevant much longer, and that they could face technological unemployment, like many other white-collar workers. Some technology leaders think white collar jobs in general are under threat, as AI automates routine office work creating financial value but eliminating jobs [Knight, 2017]. Even specialised professions, such as law, could be affected as AI lawyers start being deployed [Cellan-Jones, 2017].

The changes AI bots could unleash in science writing are remarkable. Headlines such as "The Washington Post's robot reporter has published 850 articles in the past year" [Miller, 2015], - a feat any single reporter might find hard to match highlight the potential impact. As the performance of bots improves further, editors will put more trust in them.

Most journalists I talked to are vaguely familiar with the rise of news-writing bots, but they assume science is still too complex for the bots to tackle. Not so. Take SciNote's recently released AI manuscript writer that has already written more than 100 research papers. The AI takes in the researcher's data and previous 
literature and turns it into a respectable first draft. "The feature allows me to assemble and present data in a way that can lead to a publication with only minor modifications from me," one user, Tessa Grabinski, a lab manager at University of Michigan, US, is quoted as saying on SciNote's website. "Not only does the new feature generate manuscripts quickly, it also provides several versions that can be used to assemble that perfect publication for your data."

These algorithms are good at providing context and background to each research discovery, the sort of material that may feature in a paper's introduction and discussion sections. This, incidentally, is also the sort of knowledge that can take journalists months or years to develop for each field they report on; the algorithm can do it instantaneously for any field you ask it to write about.

Why are science journalists ignoring these developments? I think they are largely unaware of the potential applications: AI and machine learning stories are usually tackled by technology reporters, so science specialists don't really have a good grasp on recent developments and what they mean for their jobs. As a consequence, they most likely think that science is too complex for bots to crack just yet. When they do hear about such technology, it seems to trigger feelings of terror and despair rather than interest and excitement: science journalists are not motivated to want bots take over their work, so if they can ignore the issue, they do.

Science press officers, science journalists' partners in crime (or arch nemeses, depending on your point of view) may be in the same boat. The 2015/16 State of the Profession survey revealed that only 7 per cent of PR practitioners consider automation to be amongst the top two challenges facing industry, yet the same study showed 79 per cent of professionals spend some or most of their time on media relations - a practice deemed to be under threat by automation, according to the UK's Chartered Institute of Public Relations [CIPR, 2016].

Science writers aside, you might wonder why no one else is deploying this technology to write science news. The field is so new that there are many other bigger and more lucrative areas for those involved to tackle first. And AI experts are notoriously expensive and in short supply: cue recent headlines about the exodus of university AI researchers to the private sector which is ready to pay much more money to be at the forefront of the AI revolution [Sample, 2017]. As the technology does trickle down to media, the big money-making beats are first to be tackled: sports, finance and politics. The Associated Press uses AI bots to write about baseball results and company earnings, for example. The science beat will inevitably follow, and some of us are already looking at the opportunities and challenges that will bring. The 4th Kavli Symposium on Science Journalism, on Technology \& Truths, in Austin, Texas this February was one of the first meetings addressing the issue head-on for a science journalist audience.

So what is happening in this field and what are the opportunities and challenges it will bring for science writers, including journalists and press officers?

One strand of research is looking at how to make life easier for science reporters, by providing them with computer-assisted reporting, software that would automatically alert them to trending topics and breaking news. A good example of this is a pilot project developed at Columbia University in the US, called Science 
Surveyor. "Our goal was to develop algorithms that could quickly characterize a related subset of the rapidly growing scientific literature and display information in clear, elegant visualizations. This could help journalists find relevant sources and see related papers and the history of the field they are reporting on," says the website developed by a team led by Marguerite Holloway, Assistant Professor and Director for Science and Environmental Journalism at Columbia University's School of Journalism.

Science Surveyor uses cutting-edge algorithms developed in collaboration between journalism academics and AI experts to characterize the scientific literature on a selected topic. It uses the abstract and citations of a peer-reviewed paper to provide journalists with context about that paper in easy-to-read visualizations. These include tips on who to call for a comment, and what other related papers have been published and when; it also attempts to estimate the trustworthiness of the new paper. Whether the actual output is useful to working journalists has yet to be determined. But it demonstrates that academics are already thinking about applications which will reach actual science reporters soon, possibly catching them unawares.

If Science Surveyor works as designed, it could provide the much-needed context and ability to evaluate the trustworthiness of a research paper at a glance - hence speeding up decision-making on what to cover and the reporting process. But it might also open up the field to non-specialist reporters: if anyone can easily gauge how trustworthy a paper is, and get a list of key science contacts in any field, who needs the know-how that seasoned science reporters develop over many years on the beat? Holloway's team designed their project to help, but how it ends up being used is anyone's guess - it might even backfire, challenging experienced science reporters' expertise and jeopardising their jobs.

On their own, AI researchers know little about science journalism, and most science journalists are not experts in computer coding or AI. AI solutions can help us take new approaches to science journalism, but given how niche our field is, it will probably take insiders, such as Holloway, to actually reach out to AI experts and companies and ask them to develop new solutions for journalism. This is where the opportunities lie: we can become actively engaged in how these new technologies are developed and we can help guide their applications.

A few of us are now looking into developing another application: an AI science news bot reporter. The technology developed for other applications can now summarise complex text and learn how to improve as it does so. Whoever develops such a bot first will have an enviable new business model: all the science news you want, when you want it, and without the cost of hiring writers, or possibly even editors. Some AI technology can compare the output with a desired template or best practice, and make amendments as required - essentially providing an editor bot, too. In the short term, though, editors will remain more essential than writers to ensure a polished final product.

The implications are huge. If you can automatically feed a new research paper into software that turns it into a news story, and possibly also provides context and background by trawling through everything ever published on that subject, as well 
as making sure it follows the news-style template better than any human could do, is there any real need for science writers anymore?

So far these advances are text-only, so they don't involve the 'reporting' step of actually talking to scientists. But one could easily build simple code that would allow you to send automatically-generated summaries to the original authors of those papers so that they could fact-check them and provide quotations (personal communication, Aleszu Bajak, Northeastern University). This is what science news reporters do: reach out to scientists, often by e-mail, to fact-check their articles and to get a quotation that they can include in their piece. So, a complete, start-to-finish science reporting bot might not be as far off as one might assume.

We're now quickly moving towards a world where content generation could take place without humans: a world in which every single research paper could come with an automatically-generated press release and a news story. It's not too far a stretch to imagine SciNote extending its service of an AI manuscript writer to include such add-ons, based on already existing technology that allows it to write research papers.

These developments might be good for sciences that are underreported now, or for opening up research from neglected regions such as Africa, for example, which lack investment and skills in their science press [Zorlu, 2012]. It might also be good for end users who may be interested in plain-language summaries of everything that's published on a niche topic of interest, be it related to their research, health, locality or anything else. And it could help science reporters by providing them with virtually endless ideas and starting points for developing into longer, more in-depth stories. One the other hand, it may mean a further overload of information, and popularization and marketing of incremental or even insignificant science. In the rush to promote everything, genuinely important papers about significant discoveries and advances might get lost in the sea of information.

And surely these developments will affect science media's current business models that science media currently operate with. It will unleash more content, meaning more competition. Could it drive many science media out of business? Will it put pressure on the salaries of those science reporters who remain in the business? How will entry-level jobs change if we no longer need inexperienced writers to write run-of-the-mill daily news discovery stories? One might hazard a guess, but these issues need urgent research. Whatever the ultimate role of AI ends up being, it will change the nature of our jobs.

One optimistic scenario is that, freed from the daily news cycle, science reporters will be able to spend more time on in-person reporting from the field, doing investigations, and spending more time on big stories that really matter and that computers can't quite manage yet. But given that investigative journalism is still struggling to find a sustainable business model that works, this vision might be a long shot.

Given how much research institutions already spend on press officers and various self-published magazines that promote and market their people and research, it seems likely that scientists and their institutions will wholeheartedly embrace AI science-writing bots - yet another, cheaper way, of doing even more 
self-promotion and communication, even if it hurts independent journalism and science PR jobs. To avoid this, science journalists need to be aware of the technology and what it can do, and start taking an active part in shaping its applications, so it helps, rather than hinders, independent, critical science journalism.

\section{References}

Cellan-Jones, R. (1st November 2017). 'The robot lawyers are here - and they're winning'. BBC News. URL: http://www . bbc. com/news/technology- 41829534.

Knight, W. (6th November 2017). 'Is Technology About to Decimate White-Collar Work?' MIT Technology Review. URL: https://www. technologyreview.com/s/60 9337/is-technology-about-to-decimate-white-collar-work/.

Marche, S. (2017). 'What Happens When an Algorithm Helps Write Science Fiction'. Wired. URL: https : //www . wired.com/2017/12/when-an-algorithm-he lps-write-science-fiction/.

Miller, R. (29th January 2015). 'AP's 'robot journalists' are writing their own stories now'. The Verge. URL: https://www. theverge. com/2015/1/29/7939067/ap-jou rnalism-automation-robots-financial-reporting.

Olewitz, C. (2016). 'A Japanese AI program just wrote a short novel, and it almost won a literary prize'. Digital Trends.

URL: https://www . digitaltrends.com/cool-tech/japanese-ai-writes-nove l-passes-first-round-nationanl-literary-prize/.

Oremus, W. (17th March 2014). 'The First News Report on the L.A. Earthquake Was Written by a Robot'. Slate. URL: http://www.slate.com/blogs/future_tense/2 014/03/17/quakebot_los_angeles_times_robot_journalist_writes_article _on_la_earthquake.html.

Sample, I. (2nd November 2017). 'Big tech firms' AI hiring frenzy leads to brain drain at UK universities'. The Guardian.

URL: https://www . theguardian.com/science/2017/nov/02/big-tech-firmsgoogle-ai-hiring-frenzy-brain-drain-uk-universities.

Sawer, P. (16th December 2017). 'Hear the one about the robot director? BBC lets AI film comedy and music shows'. The Telegraph.

URL: http://www .telegraph.co.uk/news/2017/12/16/hear-one-robot-direc tor-bbc-ai-film-comedy-music-shows/.

The Chartered Institute of Public Relations (CIPR) (12th October 2016). "“AI will compel PR professionals to upskill" - CIPR welcomes Science \& Tech Committee report'. CIPR website.

URL: http://newsroom.cipr.co.uk/ai-will-compell-pr-professionals-toupskill---cipr-welcomes-science--tech-committee-report/.

Webb, A. (2017). 'The Global Survey of Journalism's Future'. Future Today Institute. URL: https://futuretodayinstitute.com/global-survey-on-journalisms-f utures/.

Zorlu, G. (2012). 'Africa needs a science news service, says report'. SciDev.Net. URL: https://www.scidev.net/global/r-d/news/africa-needs-a-science-n ews-service-says-report.html. 
Mico Tatalovic is Knight Science Journalism fellow at MIT, where he is researching AI applications to science writing. He is on a career break from New Scientist, where he is environment and life sciences news editor. Mico is also chairman of the Association of British Science Writers and sits on the board of Balkan Network of Science Journalists. E-mail: mico@mit.edu.

How to cite

Tatalovic, M. (2018). 'AI writing bots are about to revolutionise science journalism: we must shape how this is done'. JCOM 17 (01), E.

https://doi.org/10.22323/2.17010501.

(c) The Author(s). This article is licensed under the terms of the Creative Commons Attribution - NonCommercial - NoDerivativeWorks 4.0 License.

ISSN 1824-2049. Published by SISSA Medialab. jcom.sissa.it 